\title{
Clinical translation in OCT: Role of research, funding, and entrepreneurism (Presentation Video)
}

\section{Eric Swanson}

Eric Swanson, "Clinical translation in OCT: Role of research, funding, and entrepreneurism (Presentation Video)," Proc. SPIE 8934, Optical Coherence Tomography and Coherence Domain Optical Methods in Biomedicine XVIII, 89342E (22 July 2014); doi: 10.1117/12.2064185

SPIE. Event: SPIE BiOS, 2014, San Francisco, California, United States 


\section{Clinical translation in OCT: Role of research, funding, and entrepreneurism (Presentation Video)}

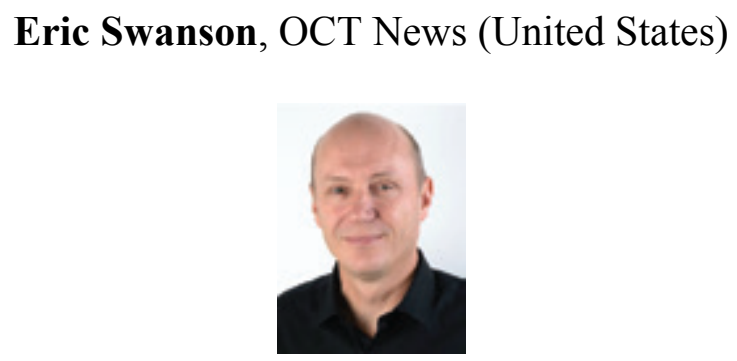

\section{BIOS 2014 Hot Topics Presentation}

Eric Swanson discusses the migration of optical coherence tomography (OCT) into clinical practice in, "Clinical Translation in OCT: Role of Research, Funding, and Entrepreneurism."

The translation from research to successful clinical impact is challenging and often the process passes through several stages including product development, initial sales and product iteration, market growth, and, finally, the next generation products. Each step can take several years, requiring persistence and perseverance on the parts of technologists and investors alike. The first release of a reliable, manufacturable, and supportable commercial product into the hands of clinicians is a critical milestone. It allows for fine tuning of the product attributes on the road to proving clinical utility and sometimes results in discovery of unforeseen applications.

Clinical translation of OCT has been impactful, scientifically, clinically, and economically. Over 20M patients per year undergo OCT diagnostic imaging and the cumulative OCT system sales over the past decade are well in excess of \$1B. Many applications remain to be commercialized could potentially further benefit healthcare and improve quality of life. Startups have played, and continue to play, an important role in the translation of new applications of OCT.

View presentation video on SPIE's Digital Library: http://dx.doi.org/10.1117/12.2064185 